\title{
Expanded Endoscopic Transnasal Approach to the Chordoid Glioma of the Third Ventricle : The First Case Ever Reported
}

\author{
Mehdi Zeinalizadeh, M.D., ${ }^{1,2}$ Seyed Mousa Sadrehosseini, M.D., ${ }^{1,3}$ Keyvan Tayebi Meybodi, M.D., ${ }^{2}$ Ali Heidari Sharifabadi, M.D. ${ }^{4}$ \\ Brain and Spinal Cord Injuries Repair Research Center (BASIR), ${ }^{1}$ Imam Khomeini Hospital, Tehran University of Medical Sciences, Tehran, Iran \\ Departments of Neurological Surgery, ${ }^{2}$ Otolaryngology, ${ }^{3}$ Pathology, ${ }^{4}$ Imam Khomeini Hospital, Tehran University of Medical Sciences, Tehran, Iran
}

Chordoid glioma of the third ventricle is a rare and challenging tumor to surgery because of its unique anatomical location and its close juxtaposition to the neurovascular structures and hypothalamus. The authors report a case of chordoid glioma of the third ventricle in a 43-year-old woman, who presented with headache and somnolence. The tumor was approached by endoscopic transnasal technique with a favorable result. Histopathologic examination disclosed a neoplastic tissue composed of eosinophilic epithelioid cells, mucinous, periodic acid Schiff-diastase positive, extracellular matrix, and scattered lymphoplasmacytic infiltrates. The best treatment option remains controversial. Customarily, the surgical route to remove chordoid glioma is transcranial; however, the undersurface of the optic chiasm and optic nerves preclude an adequate surgical visualization. In contrast, an expanded endoscopic transnasal approach provides a direct midline corridor to this region without any brain retraction.

Key Words : Chordoid glioma · Third ventricle $\cdot$ Suprasellar · Expanded endoscopic transnasal approach.

\section{INTRODUCTION}

Chordoid glioma (CG) of the third ventricle, a rare tumor with both glial and chordoid features, was described as a new pathologic entity in 1998 by Brat et al. and accepted by World Health Organization (WHO) in 2000 as a distinct glioma with grade II malignancy ${ }^{1,2,3)}$. Various morphological and clinicopathologic aspects of CG have been depicted, but there may also be other unknown features due to its rarity ${ }^{5}$. To this time, more than 70 cases of CG with different microscopic transcranial and transnasal approaches have been reported ${ }^{8}$; but, to the best of our knowledge, this is the first successful report of expanded endoscopic transnasal transplanum approach to this neoplasm.

\section{CASE REPORT}

A 43-year-old woman presented to our clinic with a history of headache and somnolence since one year, and a decrease of her vision of 6 months duration. On presentation, she was oriented with a visual acuity of $7 / 10$ and 2/10 in right and left eyes respectively. Visual fields were also involved. The profile of pituitary hormones was normal. Computed tomographic scan and magnetic resonance imaging (MRI) showed a well circumscribed, oval mass without calcification, hypointense in T1weighted and isointense in T2-weighted images, in the suprasellar area and the floor of the third ventricle. After the intravenous contrast administration, the mass enhancement was remarkable with the maximum diameter of $32 \mathrm{~mm}$ (Fig. 1). CG of the third ventricle and craniopharyngioma were the first and second diagnosis respectively.

The patient underwent an expanded endoscopic transnasal transplanum approach. The tumor was retro-chiasmatic and was extended from inferior border of chiasm into third ventricle. Resection of proximal stalk was intended in the pre-operative stage (because of involvement of proximal stalk and infundibulum). It was firm and non-suckable, so it was resected totally by micro-scissors with the aid of angled lens. Fig. 2 depicts intra-operative snapshots of tumor attachments. Dural defect was reconstructed with an overlay fascia lata graft, reinforced with standard nasal septal flap; and lumbar drainage

- Received : June 6, 2015 • Revised : November 12, 2015 •Accepted : December 6, 2015

- Address for reprints : Mehdi Zeinalizadeh, M.D.

Brain and Spinal Cord Injuries Repair Research Center (BASIR), Imam Khomeini Hospital, Tehran University of Medical Sciences, Keshavarz Blvd., Tehran 1419733141, Iran

Tel : +982166939330, Fax : +982166939330, E-mail : mzeinalizadeh@tums.ac.ir

- This is an Open Access article distributed under the terms of the Creative Commons Attribution Non-Commercial License (http://creativecommons.org/licenses/by-nc/3.0) which permits unrestricted non-commercial use, distribution, and reproduction in any medium, provided the original work is properly cited. 

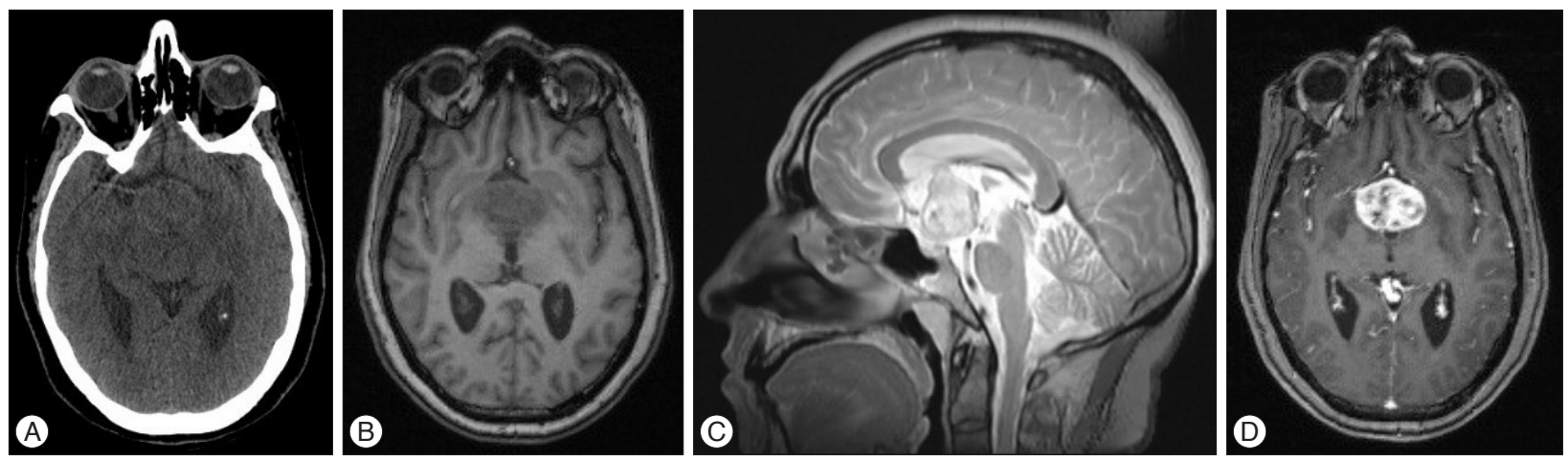

Fig. 1. A : Unenhanced axial CT scan reveals an isodense mass in the suprasellar-hypothalamic region. B, C, and D : Axial T1-weighted and sagittal T2-weighted SE MR images show a solid mass in the anterior portion of the third ventricle with non-homogeneous, intense enhancement after contrast injection.

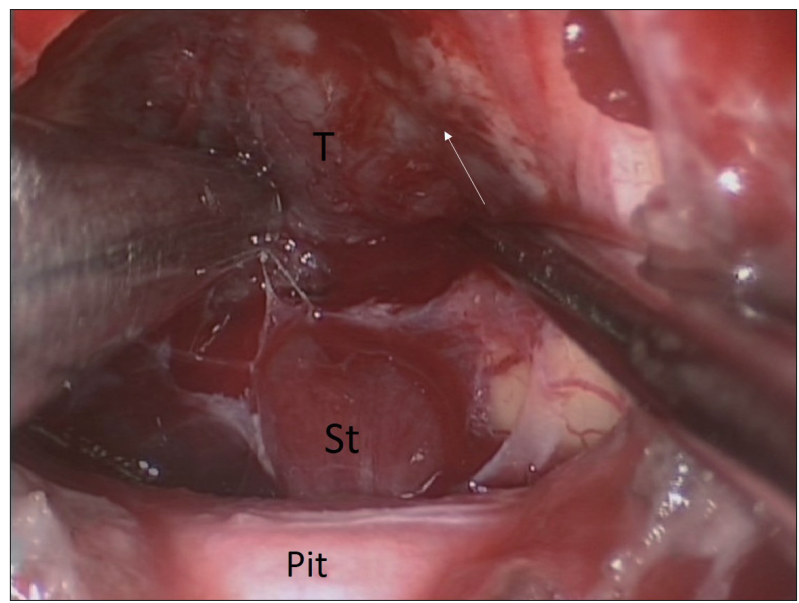

Fig. 2. Intra-operative image showing tumoral attachment to infundibulum and proximal stalk. White arrow shows the interface between the tumor and wall of the third ventricle. T : tumor, St : stalk, Pit : normal pituitary.

established for 7 days. After surgery, pituitary hormones' deficiencies replaced adequately. Of note, her somnolence got aggravated during the first postoperative week; but, improved dramatically with the administration of Ritalin (Novartis, Cambridge, MA, USA) $20 \mathrm{mg}$ per day.

Histopathologic examination disclosed a neoplastic tissue composed of eosinophilic epithelioid cells arranged in small sheets and cords, and in some areas with mucinous extracellular matrix and scattered lymphoplasmacytic infiltrates (Fig. 3A). Also, the extracellular mucinous matrix was PAS-diastase positive (Fig. 3B). Immunohistochemically, the tumor cells were diffusely positive for glial fibrillary acidic protein, vimentin, $\mathrm{CD}$ 34 , and focally positive for AE1/AE3, CK 18, epithelial membrane antigen, and S-100 (nuclear), and negative for carcino-embryonic antigen EA, NF, CK7, CK 8, CK 20, estrogen receptor, progesterone receptor, and gross cystic disease fluid protein- 15 (Fig. 3C-F). The Ki-67 labeling index was 5\%. These findings were consistent with chordoid glioma.

During the second week of her stay in hospital, she experienced a gram negative septicemia from the site of central venous catheter insertion which responded intravenous Meropenem (Daana Pharma Co., Mashhad, Islamic Republic of Iran) and Ciprofluoxacine (Samen Pharma Co., Mashhad, Islamic republic of Iran). Prior to discharge, an MRI was taken which revealed gross total tumor resection (Fig. 4).

\section{DISCUSSION}

There is a controversy over the best treatment strategy for CG : tumor biopsy/partial resection with subsequent adjuvant therapy, versus an aggressive gross total tumor resection ${ }^{7,9,11}$. Traditionally, the surgical route to remove CG is transcranial and includes transventricular, transcallosal, and translamina terminalis approaches. Lie et al. ${ }^{7)}$ in a review of 64 cases of CG demonstrated in comparrison with transventricular and transcallosal approaches, the translamina terminalis corridor was associated with a significantly lower postoperative mortality and morbidity and they concluded that apart from the neurosurgeons' experience and preferences, the translamina terminalis approach was better than the other approaches. In the usual transcranial approaches, the operative corridors through the interoptic, prechiacmatic and opticocarotid cisterns allow limited exposure, insufficient visualization, and inadequate accessibility to the infra- and retrochiasmatic regions ${ }^{1,10)}$. Further, because CG is hidden behind an anteriorly displaced chiasm, it is often mandatory to open the lamina terminalis to access this lesion in the retrochiasmatic space; therefore it could be an impressive corridor in experienced hands. However, the undersurface of the optic chiasm and optic nerves remain a blind location from the transcranial view. Instead, the expanded endoscopic transnasal approach provides a direct view to these regions ${ }^{6}$.

Selected suprasellar cases with various pathologic entities including craniopharyngiomas, pituitary stalk tumors, and basal hypothalamic lesions have been effectively approached using the expanded endoscopic transnasal technique ${ }^{4}$. Our endoscopic endonasal experience to deal with sellar and suprasellar lesions especially retrochiasmatic huge craniopharyngiomas triggered us to tackle this tumor via an endoscopic transnasal 

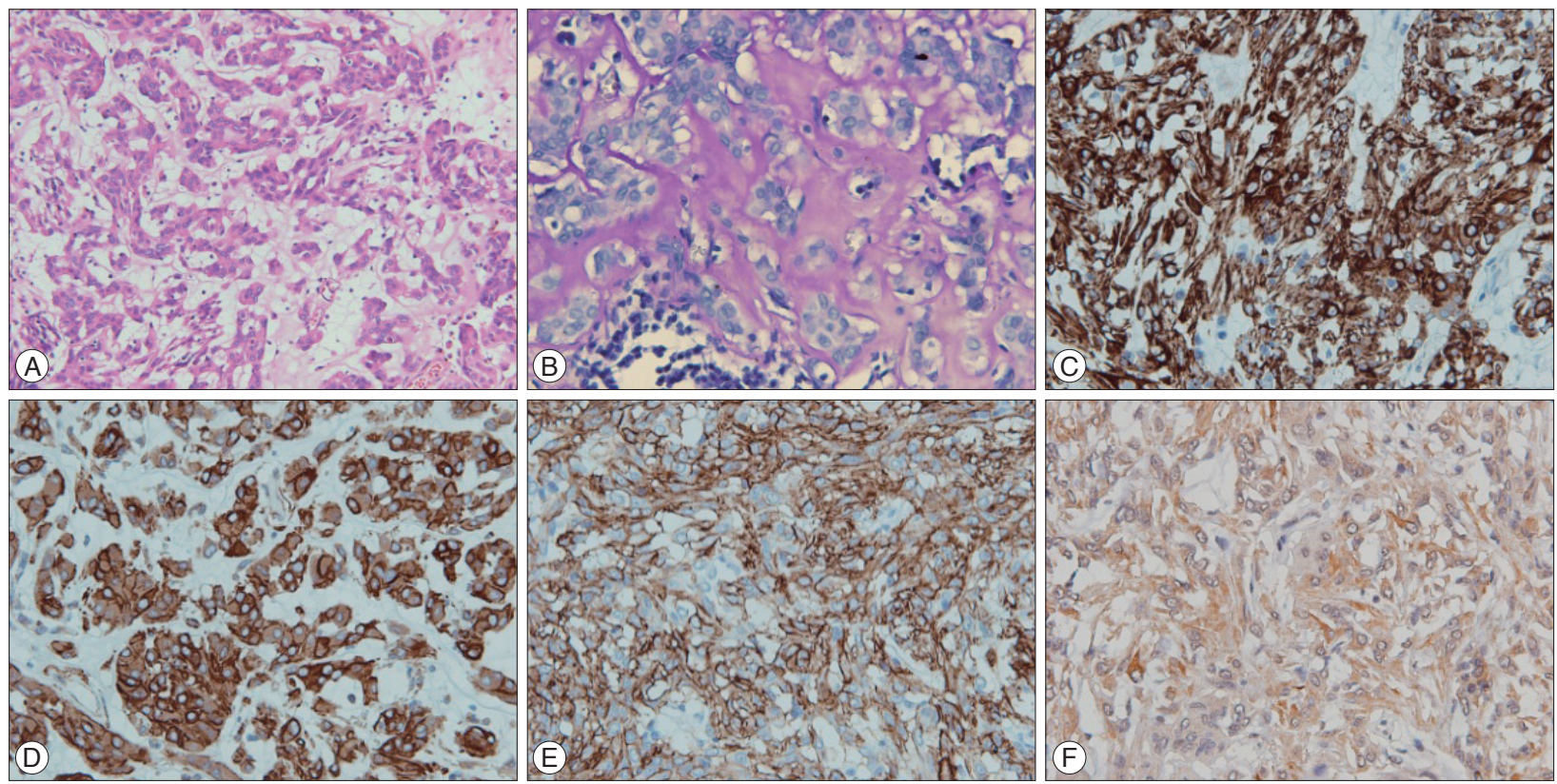

Fig. 3. A : H\&E staining $(\times 20)$ shows a neoplastic tissue composed of eosinophilic epithelioid cells arranged in small sheets and cords, and in some areas with mucinous extracellular matrix and scattered lymphoplasmacytic infiltrates. B : Extracellular mucinous matrix positivity for PAS-diastase $(\times 40)$. In immunohistochemistry $(\times 40)$, tumor cells are diffusely positive for glial fibrillary acidic protein $(C)$, vimentin (D), CD 34 (E), and focally positive for AE1/AE3 (F)
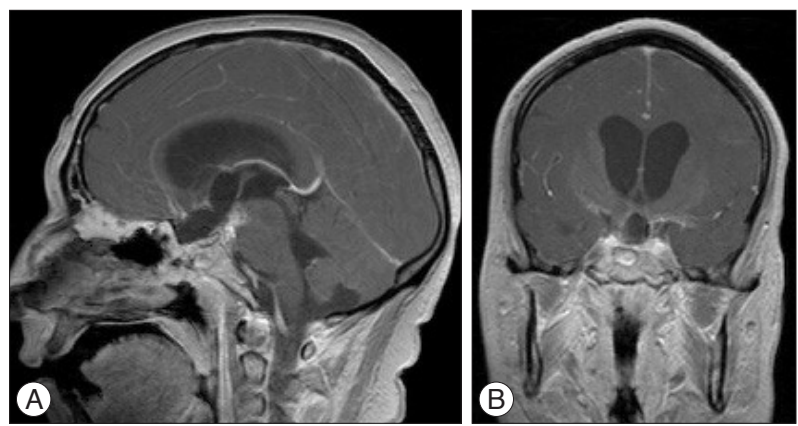

Fig. 4. Sagittal (A) and coronal (B) T1-weighted gadolinium-enhanced magnetic resonance imaging one month postoperatively showing gross total tumor resection.

route with a successful complete tumor resection. The approach and technical nuances were similar to an approach to a retrochiasmatic craniopharyngiomas ${ }^{6}$. To our knowledge, this is the first case ever reported in literature via the expanded endoscopic transnasal approach. This could be an alternative trajectory for the resection of CG; albeit, it requires an added research and study.

\section{CONCLUSION}

Chordoid glioma is a very rare tumor which occurs predominantly in middle-aged women, with a characteristic appearance on radiology and histopathology. Despite being classified as WHO grade 2, it may have a poor clinical outcome because of its close vicinity to vital structures and hypothalamus. Various transcranial approaches has been described with different rates of success. On the other side, excellent visualization of the undersurface of the optic apparatus and hypothalamus can be obtained in endoscopic transnasal approach to facilitate bimanual tumor dissection, to permit complete removal of these formidable lesions. For the first time, we present expanded endoscopic transnasal approach as an alternative route to tackle this unusual tumor with a favorable result.

\section{- Acknowledgements}

The authors wish to thank Dr. Zahid Hussain Khan for editing this manuscript.

\section{References}

1. Al-Mefty O, Ayoubi S, Kadri PA : The petrosal approach for the total removal of giant retrochiasmatic craniopharyngiomas in children. J Neurosurg 106 (2 Suppl) : 87-92, 2007

2. Brat DJ, Scheithauer BW, Staugaitis SM, Cortez SC, Brecher K, Burger PC : Third ventricular chordoid glioma : a distinct clinicopathologic entity. J Neuropathol Exp Neurol 57 : 283-290, 1998

3. Cenacchi G, Roncaroli F, Cerasoli S, Ficarra G, Merli GA, Giangaspero F : Chordoid glioma of the third ventricle : an ultrastructural study of three cases with a histogenetic hypothesis. Am J Surg Pathol 25 : 401405, 2001

4. Dehdashti AR, Ganna A, Witterick I, Gentili F : Expanded endoscopic endonasal approach for anterior cranial base and suprasellar lesions : indications and limitations. Neurosurgery 64 : 677-687; discussion 687689,2009

5. Iwami K, Arima T, Oooka F, Fukumoto M, Takagi T, Takayasu M : Chordoid glioma with calcification and neurofilament expression : case report and review of the literature. Surg Neurol 71 : 115-120; discussion 120, 2009

6. Liu JK, Christiano LD, Patel SK, Eloy JA : Surgical nuances for removal 
of retrochiasmatic craniopharyngioma via the endoscopic endonasal extended transsphenoidal transplanum transtuberculum approach. Neurosurg Focus 30 : E14, 2011

7. Liu WP, Cheng JX, Yi XC, Zhen HN, Fei Z, Li Q, et al. : Chordoid glio$\mathrm{ma}$ : a case report and literature review. Neurologist $17: 52-56,2011$

8. Ni HC, Piao YS, Lu DH, Fu YJ, Ma XL, Zhang XJ : Chordoid glioma of the third ventricle : four cases including one case with papillary features. Neuropathology 33 : 134-139, 2013
9. Sanches P, Yamashita S, Freitas CCM, Resende LAL : Chordoid glioma of the third ventricle : a new case report. Radiol Bras 45 : 288-290, 2012

10. Van Effenterre R, Boch AL : Craniopharyngioma in adults and children : a study of 122 surgical cases. J Neurosurg 97 : 3-11, 2002

11. Zarghouni M, Vandergriff C, Layton KF, McGowan JB, Coimbra C, Bhakti A, et al. : Chordoid glioma of the third ventricle. Radiology Report $25: 285-286,2012$ 